\title{
OTIMIZAÇÃO DO ARRANJO FÍSICO: UM ESTUDO DE CASO EM UMA MARCENARIA
}

\author{
Pedro Marinho Sizenando Silva ${ }^{1}$ \\ Ailton Alexandre da Silva ${ }^{2}$ \\ Priscila Ferreira Souza ${ }^{3}$ \\ Rita de Cássia Leal Campos ${ }^{4}$
}

\begin{abstract}
RESUMO
Este trabalho teve como objetivo propor um plano de reestruturação do arranjo físico a fim de maximizar a produção e proporcionar maior segurança no ambiente organizacional. Buscouse entender como o arranjo físico pode ser adaptado de maneira a propiciar um fluxo de produção efetivo e seguro. Realizou-se um estudo de caso em uma empresa do ramo moveleiro na região centro oeste de Minas Gerais que trabalha com um sistema de produção puxada. Essa possuía a necessidade de reorganização do arranjo físico e tinha como limitação o fato de estar operando em fluxo contínuo. Os resultados mostraram que a otimização do processo é possível, readaptando o arranjo físico, diminuindo a ociosidade e aumentando, assim, o aproveitamento de espaço para demarcação de áreas de movimentação com segurança.
\end{abstract}

Palavras-chave: Arranjo Físico. Segurança do trabalho. Otimização.

\section{LAYOUT OPTIMIZATION: A CASE STUDY IN A CARPENTRY}

\begin{abstract}
This work aims to propose a restructuring plan of the layout in order to maximize the production and to provide more security to the organizational environment. It sought to understand how the layout can be adapted to provide an effective and safe production flow. A case study was conducted in company in the furniture industry in the central west of Minas Gerais that works with a pull production system. The company needed to reorganize the layout and the fact that it was operating in continuous flow was its limitation. The results showed that the process optimization is possible by readjusting the layout, thus reducing the idle space and thereby increasing the space utilization to safely demarcate movement areas.
\end{abstract}

Keywords: Layout. Job Security. Optimization.

\footnotetext{
${ }^{1}$ Doutorando em Engenharia de Produção pela Universidade Federal de Minas Gerais (UFMG), Mestre em Engenharia de Produção pela UFMG. Docente efetivo no Instituto Federal de Minas Gerais - Campus Formiga. E-mail: pedro.silva@ifmg.edu.br

${ }^{2}$ Graduando do curso de Administração do IFMG - Campus Formiga. E-mail: ailtonalexandre227@gmail.com.

${ }^{3}$ Graduanda do curso de Administração do IFMG - Campus Formiga. E-mail: priscilaadm2012@hotmail.com.

${ }^{4}$ Graduanda do curso de Administração do IFMG - Campus Formiga. E-mail: ritalealcampos@yahoo.com.br.
} 


\section{INTRODUÇÃO}

Observando-se o fato de a maioria das pessoas passarem a maior parte de seu tempo no ambiente de trabalho, é de significativa importância avaliar a influência que o arranjo físico pode exercer sobre o indivíduo. Segundo Alves Filho (2011, p. 136), antes das alterações no arranjo físico, “devem-se discutir os possíveis efeitos de mudanças na estrutura organizacional, geração de capital social, gestão do conhecimento e nos aspectos físicos, cognitivos e psíquicos do trabalhador."

Há diversas variáveis que, segundo Lélis (2012), precisam ser consideradas quando se decide elaborar uma reestruturação do espaço físico. Arranjo físico é o espaço onde o processo se desenvolve. É preciso mensurar quanto de espaço cada centro precisa, afinal, se eles forem pequenos, podem prejudicar a produtividade, a privacidade dos funcionários e até a segurança.

Assim, a pergunta norteadora da pesquisa é: como o arranjo físico pode ser adaptado de maneira a propiciar um fluxo de produção efetivo e seguro?

Para responder a essa pergunta, realizando um estudo de caso, escolheu-se uma marcenaria que há 24 anos executa trabalhos de produção de móveis planejados sob encomendas, na cidade de Formiga, MG. No local, existem dois galpões que totalizam aproximadamente 550 metros e oito funcionários diretos.

\section{REFERENCIAL TEÓRICO}

\subsection{Arranjo físico}

O arranjo físico diz respeito ao posicionamento físico dos seus recursos transformadores. Isso significa decidir onde colocar todas as instalações, as máquinas, equipamentos e o pessoal da operação. É geralmente aquilo que se nota ao entrar em uma unidade produtiva, porque ele determina a aparência da operação (SLACK; CHAMBERS; JOHNSTON, 2007).

O arranjo físico deve ser capaz de propiciar condições para um ambiente com produção eficaz, com condições seguras para realização do trabalho. Portanto, seu estudo com outros temas é essencial, pois de acordo com Alves Filho (2011) são muitas as variáveis 
relacionadas com uma alteração na disposição dos movimentos e dos contatos dos trabalhadores dentro de uma empresa.

Segundo Ritzman e Krajewsky (2004), as consequências de uma mudança de arranjo físico, salientando que esse pode afetar a organização e o modo como ela atinge suas prioridades competitivas, são:

a) Facilitar os fluxos de materiais e informações;

b) Aumentar a conveniência do cliente, as vendas em uma loja varejista, bem como a moral dos funcionários e melhorar a comunicação.

Existem ao menos três tipos básicos de arranjo: arranjo por processo ou funcional; arranjo por produto ou em linha; arranjo híbrido ou misto. $\mathrm{O}$ “arranjo por processo é mais usual quando a mesma operação precisa produzir de modo intermitente muitos produtos diferentes ou atender a muitos clientes diferentes." (RITZMAN; KRAJEWSKY, 2004, p. 198).

Já o arranjo por produto ou em linha, segundo Slack, Chambers e Johnston (2007, p. 189) “[...] envolve localizar os recursos produtivos transformadores inteiramente segundo a melhor convivência do recurso que está sendo transformado". De acordo com esse autor, a característica uniforme dos requisitos do produto ou serviço é que leva a esse tipo de arranjo físico.

O tipo de arranjo híbrido é usado em operações de produção e montagem. As operações de fabricação nas quais os componentes são feitos a partir de matérias primas, possuem fluxo desordenado, ao passo que as operações de montagem nas quais os componentes são montados em produtos finais, possuem um fluxo linear (RITZMAN; KRAJEWSKY, 2004, p. 199).

O tipo de arranjo físico a ser aplicado em determinado ambiente deve ser escolhido de maneira que atenda às necessidades da organização, tornando a produção eficiente e propiciando segurança aos envolvidos no processo.

\subsection{Segurança do trabalho}

Um dos problemas encontrados na organização estudada foi a falta de segurança no trabalho. Existe, no ambiente operacional, periculosidade que, segundo Martins (2013), tratase da possibilidade de ocorrer o infortúnio. Ressalta-se que: 
[...] todo estabelecimento deverá estar equipado com material necessário à prestação de primeiros socorros, considerando-se as características da atividade desenvolvida. O material deverá ser guardado em local adequado e aos cuidados da pessoa treinada para esse fim. (MARTINS, 2013, p. 718)

Segundo Martins (2013), o empregador deve adquirir o tipo adequado de epi"s, às atividades do empregado - vários no caso da empresa (protetor auricular, luvas, máscaras, calçados, óculos, vestimentas), treinar o trabalhador para o seu uso, substituí-lo quando danificado ou extraviado e tornar obrigatório seu uso, visando sempre à segurança e à proteção do trabalho, com conscientização diária.

\section{METODOLOGIA}

A abordagem utilizada na pesquisa é a qualitativa, que para Richardson (1999) pode descrever a complexidade de determinado problema, analisar as interações de certas variáveis, compreender e classificar processos dinâmicos vividos por grupos sociais.

Realizou-se estudo de caso, utilizando-se de entrevistas não estruturadas, uma forma de explorar mais amplamente uma questão. Para isso, foram feitas diversas observações diretas, devido à variação dos fluxos de atividades e à importância do conhecimento do fluxo para a proposição de alterações do arranjo físico. Segundo Gil (2010), esse processo consiste na observação direta do ocupante do cargo, no exercício de suas funções, e possui como vantagem a garantia da veracidade dos dados obtidos; não requer do ocupante do cargo paralisação do trabalho, possuindo como desvantagem o tempo demandado para tarefas complexas. Neste estudo de caso optou-se por utilizar esse tempo para aumentar a fidelidade dos dados relativos ao fluxo de processo.

Após identificar os fluxos do processo, estudar sobre os tipos existentes de arranjo físico, normas regulamentadores, especificações dos maquinários e obter informações sobre o arranjo físico atual, deu-se início ao trabalho de pesquisa bibliográfica e estudo de caso.

\section{RESULTADOS}

Os resultados mostraram que há possibilidade de aperfeiçoar o processo, readaptando o arranjo físico, diminuindo, assim, a ociosidade de espaço, o que gerou maior aproveitamento de espaço para demarcação de áreas de movimentação. 
Para isso propôs-se um novo arranjo físico, com modificações no espaçamento entre máquinas e delimitação de faixas de segurança, representado na Fig. 2. Para observação da dimensão do espaçamento atual, bem como a localização das máquinas, a Fig. 1 representa o arranjo físico atual.

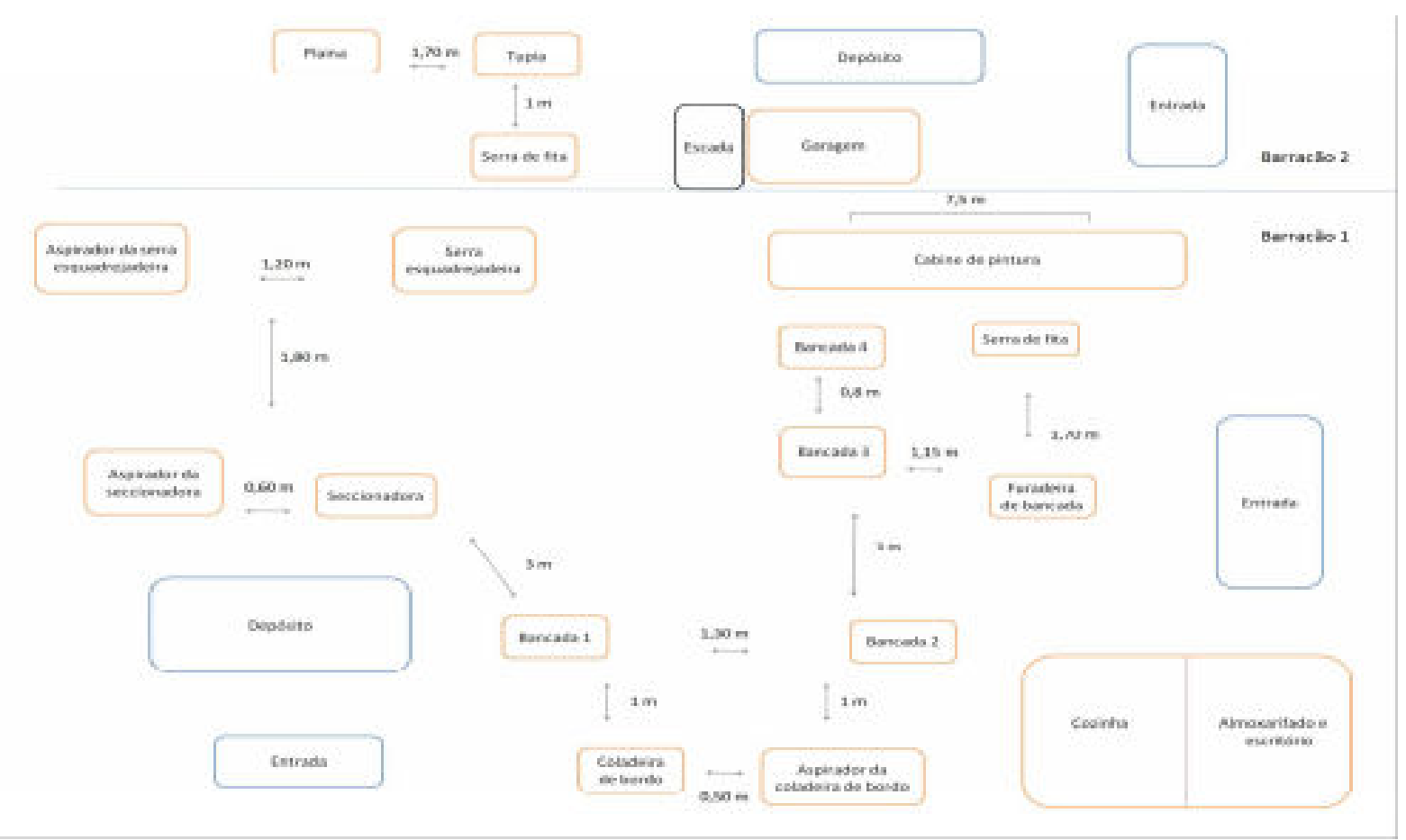

Figura 1- Arranjo físico atual

Fonte: Elaborado pelos autores.

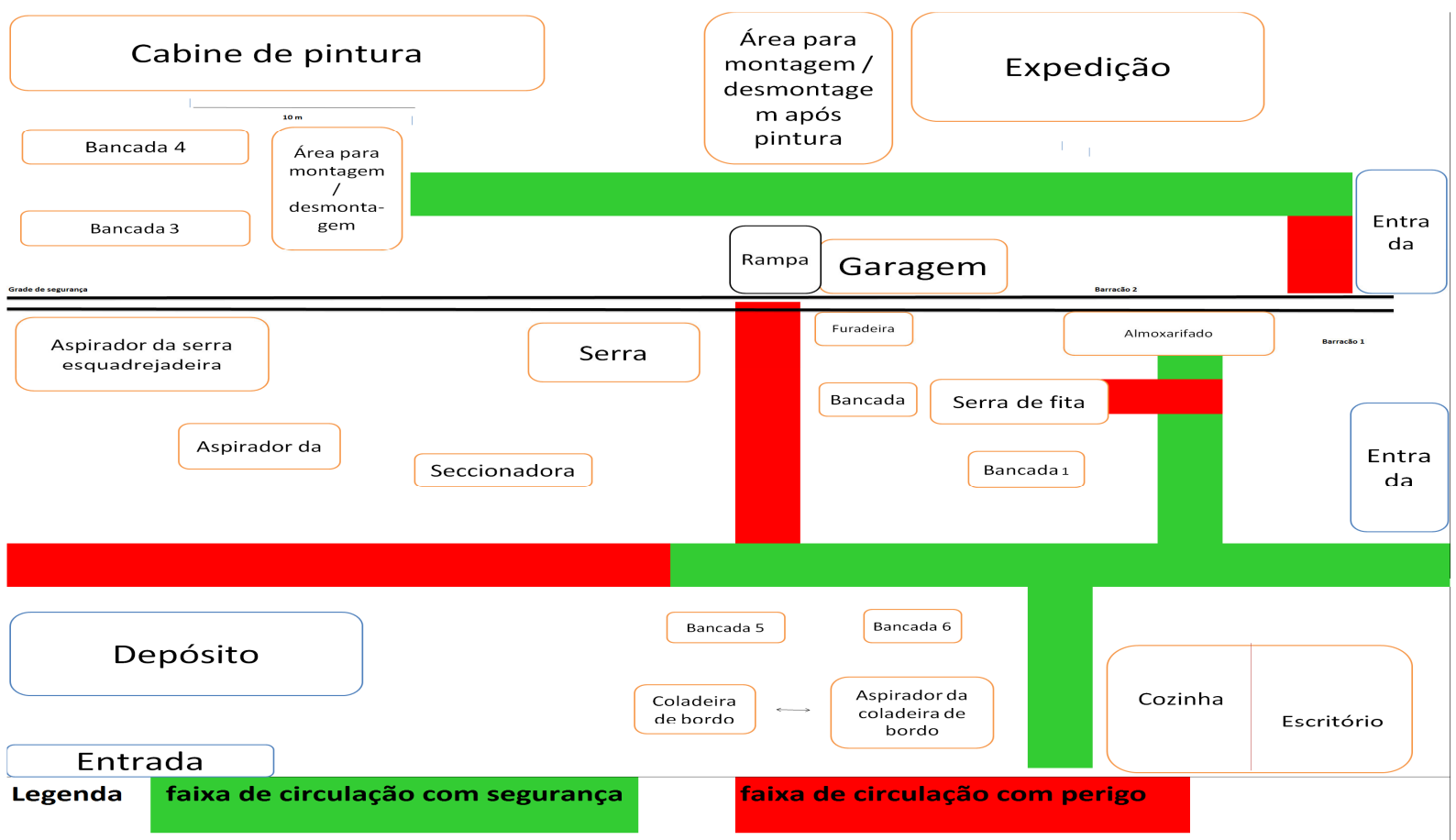

Figura 2 - Arranjo físico proposto

Fonte: Elaborado pelos autores.

ForSci.: r. cient. IFMG campus Formiga, Formiga, v. 2, n. 2, p. 24-30, jul./dez. 2014. 


\section{CONCLUSÃO}

Após observações no arranjo físico atual, bem como nos fluxos de atividades, chegouse a conclusão de que o arranjo físico é fruto de um crescimento repentino, sem que houvesse um planejamento elaborado de ampliação e adequação da estrutura.

Indicaram-se algumas alterações, como deslocamento de máquinas de menor peso, aquisição de novas bancadas, mudança da cabine de pintura, bem como de parte do processo. Observou-se que essas modificações não representariam a solução mais eficiente de reestruturação do arranjo físico atual da empresa, porém, mediante as limitações, essa seria a proposta mais eficaz.

Ao trabalhar-se com um arranjo híbrido é possível proporcionar um ganho de aumento no espaço de circulação possibilitando a implantação de faixas de circulação e liberação de corredores. Dessa maneira, é possível proporcionar maior segurança e redução de tempo e movimento. Possibilita-se também melhora significativa na eficiência produtiva, bem como uma maximização da segurança no trabalho.

\section{REFERÊNCIAS}

ALVES FILHO, B. de F. Processos organizacionais: simplificação e racionalização: São Paulo: Atlas, 2011.

GIL, A. C. Gestão de pessoas: enfoque nos papéis profissionais. São Paulo: Atlas, 2010.

LÉLIS; E. C. Administração da produção. São Paulo: Pearson, 2012.

MARTINS, S. P. Direito do trabalho. 29. ed. São Paulo: Atlas, 2013, 979 p.

RICHARDSON, R. J. Pesquisa social: métodos e técnicas. 3. ed. São Paulo: Atlas, 1999.

RITZMAN, L. P; KRAJEWSKY, L. J. Administração da produção e operações. São Paulo: Pearson, 2004.

SLACK, N.; CHAMBERS, S.; JOHNSTON, R. Administração da produção. 3. ed. São Paulo: Atlas, 2007. 
Recebido em: 16/11/2014 Aprovado em: 28/11/2014

Publicado em: 26/01/2015 